\title{
Word to the mother(tongue): language access and Medicaid for Limited English Proficient migrants
}

\author{
Wayne Liou (1)
}

Correspondence: wliou@hawaii.edu Department of Economics,

University of Hawai'i - Mānoa, 2424 Maile Way, Honolulu, USA

\begin{abstract}
Limited language proficiency among migrants has been shown to limit migrants from various aspects of everyday life, from the labor market to government services. In the USA, language access laws have been enacted to help provide Limited English Proficient (LEP) individuals and households access to public benefits. The most extensive efforts in language access are in health care, with numerous states requiring Medicaid agencies to provide interpreters or translated documents. In this paper, I take advantage of heterogeneity in state-level language access laws to examine whether these efforts do indeed increase Medicaid take-up rates. I find that language access improves Medicaid take-up rates among LEP migrants without crowding out private health insurance; in fact, private health insurance coverage improves with the enactment of language access laws. There is some variation in efficacy across states, with some evidence that California and New York are the main drivers of the increased take-up rates. Lastly, I find that even though many of the language access laws primarily target Spanish speakers, the laws might not be as helpful to Spanish-speaking migrants.
\end{abstract}

JEL classification: $113,118, J 15$

Keywords: Immigrants, Language access, Government services, Medicaid

\section{Introduction}

While the benefits to having migrants proficient in the language of their destination has been repeatedly shown in the literature (Chiswick 1991; Angrist and Lavy 1997; Bleakley and Chin 2004), the number of migrants who have a hard time learning and speaking this destination language is still quite large. For example, the USA's Limited English Proficient (LEP) migrants made up $8 \%$ of the total US population as recently as 2013 (Zong and Batalova 2015). The inability to communicate effectively does not have to constrain; however, institutions and organizations in the destination country can provide language interpretation and translation services, also known as language access, to these migrants. For example, the USA has emphasized the importance of accommodating migrants who are not proficient in English: Title VI of the 1964 Civil Rights Act states that "[n]o person in the United States shall, on the ground of race, color, or national origin, be excluded from participation in, be denied benefits of, or be subject to discrimination under any program or activity receiving Federal financial assistance" (Pub. L. 88-352, title VI, Sec. 601, July 2, 1964, 78 Stat. 252). Executive Order 13166, issued in 2000, clarified Title VI's national

(c) The Author(s). 2018 Open Access This article is distributed under the terms of the Creative Commons Attribution 4.0 International License (http://creativecommons.org/licenses/by/4.0/), which permits unrestricted use, distribution, and reproduction in any medium, provided you give appropriate credit to the original author(s) and the source, provide a link to the Creative Commons license, and indicate if changes were made. 
origins aspect, stating "each Federal agency shall examine the services it provides and develop and implement a system by which LEP persons can meaningfully access those services consistent with, and without unduly burdening, the fundamental mission of the agency" (Executive Order 13166).

In theory, these two laws mean that language access should be provided in many cases. Title VI applies broadly, regardless of whether federal funding is direct or indirect and the amount of funds received. According to Youdelman (2009), "in the health care context, this includes virtually all: hospitals; doctor's offices; nursing homes; managed care organizations; state Medicaid agencies; home health agencies; health insurance providers; and social services organizations" [p.2], but in reality, Perkins and Youdelman (2008) argue that "[d]espite such federal requirements, lack of knowledge and enforcement leave millions of LEP individuals without meaningful access to health care" [p.4].

To combat the limited knowledge and enforcement of Title VI, all states have passed some degree of language access laws in the health care industry. The amount of language access varies greatly across states, however. Some states have enacted comprehensive Title VI-like laws for state agencies, while some states merely require information pamphlets on a variety of diseases be translated. Provisions also include rules on interpreter certification and facility licensure, access plans, and rights at hearings. To see if language access plays a role in the goal of extending health insurance coverage, I take advantage of the heterogeneity in state-level language access laws to analyze whether language access laws requiring translation services at Medicaid agencies increases Medicaid take-up rates for LEP migrants. Due to the similarities between the State Children's Health Insurance Program (SCHIP) and Medicaid ${ }^{1}$, "Medicaid" from now on means non-Medicare, nonmilitary public health insurance. To my knowledge, this is the first paper to look into the effects of language access on access to government services. This is also the first paper to examine individual outcomes from language access/barriers in health care using public use microdata. My main result is that language access improves Medicaid take-up rates among LEP migrants. What is more, there is no evidence of government crowd-out; private health insurance coverage even increases after the passage of language access laws. The effect of the different state laws varies across states, and the main results could be driven by New York and California. Furthermore, even though many of these translation services primarily target Spanish speakers, the results suggest that the laws are not more helpful to Spanish-speaking migrants.

\section{Literature review}

This paper fits into the scarce literature on the importance of language in accessing health care. There is some literature on adverse health outcomes from being unable to communicate with doctors and nurses effectively, primarily published in the biomedical and life science fields. These articles usually point to how language barriers contribute to a low level of understanding of diagnoses and treatment options (Hadler et al. 2013; Khan et al. 2013). In a technical report, Quan and Lynch (2010) examines how costly language barriers are when miscommunication leads to medical malpractice. Analyzing the medical malpractice claims of a malpractice carrier that insures in four states, Quan and Lynch (2010) identified 35 closed claims that involved language barriers from January 2005 through May 2009, 2.5\% of total claims reviewed by the malpractice carrier. These claims resulted in over $\$ 5$ million in damages, settlements, and legal fees. The 
lack of malpractice carriers providing interpreters to hospitals to reduce these types of claims could, ironically, be a case of adverse selection. Providing interpreters would likely increase the costs of using the malpractice carrier, and hospitals that deem themselves to have little need for interpreters would not pay higher costs for a malpractice carrier that offers interpreters the hospitals consider unnecessary. This affects the malpractice carrier's risk pool, as it insures hospitals that are increasingly more likely to need interpreters. In this analogy, hospitals with little need for interpreters are healthy people, and malpractice carriers with interpreters are health insurance agencies.

There is also some literature regarding immigrants' lower rates of obtaining health insurance. A Migration Policy Institute report by Ku and Jewers (2013) illustrates the disparity of health insurance and health care access between immigrants and native-borns. In 2011, 62\% of non-citizen low-income adults (ages 19 to 64) were uninsured, compared to $42 \%$ of naturalized citizens and $35 \%$ of native-borns ( $\mathrm{Ku}$ and Jewers 2013, Figure 2). Foreign-borns made approximately $20 \%$ fewer office-based medical visits than nativeborns (Ku and Jewers 2013, Figures 3 and 4). Ku and Jewers (2013) point out that while these differences could be due to income differences and eligibility restrictions placed on non-citizens, they also stress the importance of language barriers, particularly with regard to communication between patients and clinicians. Feinberg et al. (2002) more carefully examine the language access issue in obtaining Medicaid, examining the effects of language barrier on education and outreach and initial enrollment. They find that the major barriers to Medicaid enrollment related to "know-how' - that is, knowing about the Medicaid program, if their child was eligible, and how to enroll" (Feinberg et al. 2002, p.5).

\section{Data and methodology}

There are three main pieces to the puzzle of whether language access improves Medicaid take-up rates for LEP migrants: if the individual is enrolled in Medicaid, if the individual is an LEP migrant, and whether the state the individual resides in is treated by having language access laws that would affect Medicaid accessibility. The data come from the Current Population Survey (CPS), which has rich data about health insurance coverage. The sample period covers 1994-2008. Unfortunately, the CPS has no English proficiency question, so English proficiency has to be inferred from other survey questions. First, I look at where an individual was born. Individuals born in countries that do not have English as an official, primary, or widely spoken secondary language clearly are more likely to be LEP. This standard for identifying LEP individuals is obviously limited; some countries, such as India, do not have a large English-speaking population in general, but educated individuals almost all speak English. ${ }^{2}$ Further, Chiswick and Miller (2001) find evidence that education increases destination-language skills. Thus, I do not consider respondents with a high school degree or higher as LEP. Lastly, considering the "critical period" of second language acquisition as in Bleakly and Chin $(2010,2004)^{3}$, I use an individual's year of arrival, age, and year of survey to determine the individual's age of arrival. If the individual arrived in the USA prior to 9 years of age, I do not consider them as LEP. Unfortunately, this identification strategy probably misidentifies some LEP individuals in both directions; some individuals identified as LEP by these standards might be fluent in English, for example, by moving to an English-speaking, non-US country prior to age 9. Conversely, some individuals identified as being proficient English 
speakers by this strategy might actually be LEP, as might happen in ethnic enclaves (Chiswick and Miller 2005).

At its most basic, this paper is analyzing whether legally mandated translation services assist LEP adults in accessing health services for themselves and their children. Translation assistance does not always come from policy-mandated interpreters or translated documents, however. Someone who is not fluent in English could live in a household that has a proficient English speaker who can provide translation services for them; language access laws should not affect these types of LEP individuals. Alternatively, children born in an English-speaking country might be proficient in English but have parents who are not English proficient. In this scenario, the child is proficient in English, is too young to understand the application process, has LEP parents, and therefore would likely be affected by language access laws. To address these two cases, I look at whether all adults, defined as being older than 16 years of age, in a household are LEP. If at least one adult in the household is not LEP, then all members in the household are recoded as not being LEP. If all adults in the household are defined as LEP, the children are all recoded as being LEP.

To determine whether a state is considered treated by a language access state in a particular year, I go through the list of state laws provided in Perkins and Youdelman (2008) and find state laws that should, in theory, increase access to Medicaid. I look for laws that require Medicaid agencies to provide translated documents, interpreters throughout the application process, or non-English advertisements and notifications of eligibility. There are 28 "states" (27 states and the District of Columbia) that, as of 2008, have some degree of improved language access to Medicaid ${ }^{4}$; of these 28 , I was able to find the date of enactment for 22 states. See Additional file 1 for the list of states with improved language access to Medicaid, what the content of these laws are, and when the laws were enacted.

Careful attention is paid to two particular types of language access laws that might have minimal effects on Medicaid take-up rates. The first type of laws are laws that require Medicaid providers and/or affiliates to have an access plan that addresses language access issues. The language of these laws generally do not explicitly require that the organization improve access, they merely require a plan that includes the organization's efforts to address access needs. In other words, it seems that a plan stating that limited to no efforts are being made to address the needs of LEP migrants seeking coverage would still be in compliance with the law. Any minimal effort to actually provide translation services would have minimal effects on Medicaid take-up rates. The second type of laws are laws that affect certain segments of Medicaid seekers or enrollees. For example, in Indiana and Mississippi, language access laws were passed for health maintenance organizations (HMOs) but not for Medicaid carriers as a whole. If some, but not all, Medicaid benefits are distributed via HMOs, the impact of these language access requirements might be limited on Medicaid take-up rates. In Tennessee, only those who are already enrolled in Medicaid can obtain translation assistance; would this increase Medicaid take-up rates, since LEP migrants seeking Medicaid coverage do not receive government-mandated language access? I consider the states as treated for the purpose of this analysis, to estimate a lower bound of the treatment effect. Additional file 1 makes note of the states with laws that possibly have a limited effect on Medicaid take-up rates.

Pre-treatment characteristics are compared between states that have passed Medicaid access-improving language access laws and states that have not to see if there are any 
systemic differences between the two. I use 1970 as the year to compare pre-treatment characteristics because the immigration literature uses the stock of migrants in this year as an instrument to control for the endogeneity of immigrants' migration decisions (Altonji and Card 1991). The variables chosen reflect the size of the migrant population, particularly with respect to migrants who are less likely to speak English, and economic conditions that migrants might consider in their migration decision. The party affiliation of the governor is used to capture the political atmosphere that might encourage or discourage the passage of migrant-friendly laws.

An important concern for this paper is the exogeneity of the language access laws. States with large LEP populations might have more incentive to pass language access laws to accommodate the large number of LEP migrants residing in the state. I run two tests to address the issue of whether the passage of language access laws is exogenous from factors such as the size of the LEP population. First, I use covariates from a pre-treatment year to see if these affect the number of all health care-related language access laws, not just Medicaid access laws, in a state in 2008. This is a broad measure of whether factors that could affect attitudes towards LEP migrants affect the passage of language access laws. For the second test, I focus in on the states that have passed Medicaid access-improving laws, using the approach of Hoynes and Schanzenbach (2009) and Bailey (2012) to predict the timing of when these language access laws are passed. This test involves regressing the law's year of passage on pre-treatment covariates; statistically significant coefficients would suggest possible problems with endogeneity. Both tests use the 1970 pre-treatment characteristics in Table 1. Results from these two tests are in Appendix 1; there is litthe evidence that the number and timing of these language access laws are predictable; thus, I consider the timing of these Medicaid access-improving language access laws as exogenous. Summary statistics are in Table 2.

To analyze the effects of language access on Medicaid take-up rates for LEP migrants, I use a difference-in-differences strategy, comparing Medicaid enrollment between LEP and non-LEP migrants before and after language access laws are enacted. I run a linear probability model on the following regression to evaluate the effects of language access laws on the Medicaid take-up rates of LEP migrants:

$$
M E D_{i, t}=\beta_{0}+\beta_{1} L A_{i}+\beta_{2} L E P_{i, t}+\beta_{3}(L A * L E P)+\theta X_{i, t}+\gamma_{1} T_{t}+\gamma_{2} S_{i}+\varepsilon_{i}
$$

where $M E D_{i, t}$ is an indicator variable that is 1 when an individual $i$ has Medicaid in time period $t$ and a 0 otherwise, $L A_{i, t}$ is the treatment variable that is 1 when the

Table 11970 characteristics

\begin{tabular}{llll}
\hline & $\begin{array}{l}\text { Has Medicaid access- } \\
\text { improving language } \\
\text { access laws }\end{array}$ & $\begin{array}{l}\text { No Medicaid access- } \\
\text { improving language } \\
\text { access laws }\end{array}$ & Difference (has-no) \\
\hline \% foreign-born & 0.0449 & 0.0412 & 0.0037 \\
\% born in non-English speaking country & 0.0348 & 0.029 & 0.0058 \\
\% with English as mother tongue & 0.9016 & 0.9029 & -0.0013 \\
Employed-to-unemployed ratio & 23.312 & 23.278 & 0.034 \\
Total family income & $10,254.62$ & $10,245.18$ & 9.44 \\
Governor's party & 1.642 & 1.609 & 0.033 \\
\hline
\end{tabular}

Notes: Democrat $=1$, Republican $=2$ for "Governor's party"

a Includes four states whose date of passage could not be found. There is no statistically significant difference between the means for all the variables 
Table 2 Summary statistics of individuals with deflated household income of less than $\$ 25,000$ (2008 base year)

\begin{tabular}{lllll}
\hline Sample & All & $\begin{array}{l}\text { Limited English } \\
\text { Proficient migrant }\end{array}$ & $\begin{array}{l}\text { LEP in state with } \\
\text { language access }\end{array}$ & $\begin{array}{l}\text { LEP in state without } \\
\text { language access }\end{array}$ \\
\hline$n$ & 81,862 & 35,276 & 21,436 & 12,448 \\
Age & 24.48 & 23.03 & 23.10 & 23.27 \\
Female & 0.53 & 0.52 & 0.53 & 0.52 \\
No. of ppl in hh & 3.85 & 4.11 & 4.16 & 4.02 \\
Marital status & & & 0.62 & 0.62 \\
Never married & 0.60 & 0.62 & 0.29 & $14,122.3$ \\
Married & 0.29 & 0.28 & $14,504.59$ & 0.36 \\
Deflated household income & $14,418.29$ & $14,384.62$ & 0.44 & 0.17 \\
Have Medicaid/SCHIP & 0.37 & 0.41 & 0.14 & \\
Have private insurance & 0.21 & 0.16 & &
\end{tabular}

individual lives in a state that has a Medicaid-access-improvement law as described below at time $t$ and 0 otherwise, and $L E P_{i}$ is a dummy variable that is 1 when an individual is considered Limited English Proficient (LEP), thus treated by the language access laws, and 0 otherwise. The $L A_{i, t}$ variable is turned on the year after enactment, as some of these laws are passed later in the year, after when the survey data is collected. The regression includes a vector of individual characteristics $X_{i, t}$; year and state fixed effects $T_{t}$ and $S_{i}$, respectively; and a classical error term $\varepsilon$. The vector of individual characteristics for $X_{i, t}$ is comprised of age, gender, race, education, marital status, and the number of people in the household. The coefficient of interest is $\beta_{3}$, on the $L A * L E P$ interaction term; if language access laws $\left(L A_{i, t}=1\right)$ result in LEP migrants $\left(L E P_{i}=1\right)$ increasing the probability of receiving Medicaid coverage, $\beta_{3}$ will be positive.

Individuals in households where all adults are foreign-born and have no high school degree are used as the control. In an attempt to ensure the sample contains only individuals who should be getting Medicaid, I focus on people younger than 65 years of age and in "low-income" households. There is quite a variation among states and years as to what the income cutoff is for Medicaid eligibility. The cutoff also depends on the size and make-up of the household. Since I could not find the Medicaid eligibility rules for all states across the entire sample years, I use a very broad cutoff: deflated household income (2008 base year) of $\$ 25,000$ is set as the cutoff. This cutoff is adjusted to ensure that any results are not driven by the cutoff level. The income cutoff is set at $\$ 25,000$ because this is just above the federal cutoff rate for poverty for a household of four people in 2008 . For the most part, non-pregnant individuals above the age of 6 are eligible for Medicaid if the household income is less than the federal poverty level; children under 6 years of age are eligible for Medicaid if the household income is less than $133 \%$ of the federal poverty level, and pregnant women are eligible if household income is less than $200 \%$ of the federal poverty level. One does not necessarily need to be an American citizen to obtain Medicaid benefits-in all states, immigrants who have been in "qualified" immigrant status for 5 years or more are eligible, while some states cover benefits even if an immigrant is "not qualified." Obtaining an immigrant's status is all but impossible from the CPS, so I do not 
attempt to limit the sample by "qualified" immigrant status. Medicaid take-up rates for these individuals do not follow a perfectly parallel trend between 1994 and 2008, particularly in states with small migrant populations. The variation for these states with small migrant populations is likely due to sampling. Going from 0 out of 1 migrants enrolled in Medicaid in 1 year to 2 out of 2 the next year is as dramatic of a change in take-up rates as possible but is probably not indicative of how Medicaid take-up rates are actually evolving. Disregarding the trends in Medicaid take-up rates of states with small migrant populations, which might be sensitive to small changes in the survey data, and the trends for the other states are similar.

Two significant changes to the Medicaid program might create problems with using 1994-2008 as the sample years. The first change is the creation of the State Children's Health Insurance Program (SCHIP) in 1997, which expanded health insurance coverage for children and works as somewhat of a complement to Medicaid. Due to this close relationship with Medicaid, the dependent variable considers SCHIP enrollment as Medicaid enrollment; thus, pre-1997 Medicaid enrollment is lower simply due to the lack of enrollment in (existence of) SCHIP. The second change is the Deficit Reduction Act of 2005, which required anyone seeking Medicaid to prove that he is a US citizen or resident alien. The emphasis on distributing Medicaid to US citizens or resident aliens could have lowered take-up rates for LEP migrants. Restricting the sample to 1998-2005 would reduce the already limited variation in state laws that I have: four states have enactment start in 1998 and another five states have enactment in 2005 or later, in addition to the five states with pre-1994 enactment. However, these two changes could have an effect, particularly the creation of SCHIP, so I run separate regressions with a smaller 1998-2005 sample.

\section{Results}

Initial results (Table 3, column 1) show that language access laws increased Medicaid take-up rates among LEP individuals by 1.8 percentage points. Approximately $37 \%$ of the sample has Medicaid, so an increase of 1.8 percentage points is equal to an increase of almost 5\%. A survey of literature by Sommers et al. (2012) estimating the national takeup rates found national rates to be between 30 and $80 \%$. To ensure that the results are not driven by the income cutoff I chose, I run Eq. 1 with various cutoff levels: 20,000; 22,500; 27,500; and 30,000. Results are in Table 3. For all but the highest of these income cutoffs, the coefficient of interest is positive and statistically significant, indicating that language access laws have a positive effect on Medicaid take-up rates. The effect of language access on Medicaid take-up rates for LEP migrants decreases at the higher income cutoff levels, but this is not unexpected; by increasing the cutoff level, I am including more and more individuals who might not satisfy Medicaid eligibility requirements and thus would be unaffected by language access laws.

When the sample is reduced to 1998-2005, to reduce the impact SCHIP and the Deficit Reduction Act of 2005 might have on the results, the coefficients show no effect of language access on Medicaid take-up. The coefficients on the $L A * L E P$ interaction are all positive, but they all lose significance. When changing the sample to 1998-2008 and 1994-2005 to see if the loss of significance is more likely due to the introduction of SCHIP or because of the Deficit Reduction Act of 2005, the results indicate that SCHIP could be the primary driver of the initial results-limiting the sample to the 
Table 3 Language access and Medicaid take-up rates

\begin{tabular}{llllll}
\hline \multirow{2}{*}{ Income level cutoff } & $(1)$ & $(2)$ & $(3)$ & $(4)$ & $(5)$ \\
\hline LA & 25,000 & 20,000 & 22,500 & 27,500 & 30,000 \\
\hline LEP & $-0.0209^{* *}$ & $-0.0264^{* * *}$ & $-0.0176^{*}$ & $-0.0234^{* * *}$ & $-0.0208^{* * *}$ \\
& $(0.00860)$ & $(0.0102)$ & $(0.00933)$ & $(0.00793)$ & $(0.00749)$ \\
LA*LEP & $0.0138^{* *}$ & 0.00362 & 0.0108 & $0.0164^{* * *}$ & $0.0200^{* * *}$ \\
& $(0.00662)$ & $(0.00777)$ & $(0.00713)$ & $(0.00617)$ & $(0.00585)$ \\
Age & $0.0182^{* *}$ & $0.0250^{* * *}$ & $0.0195^{* *}$ & $0.0121^{*}$ & 0.00994 \\
& $(0.00742)$ & $(0.00869)$ & $(0.00798)$ & $(0.00692)$ & $(0.00654)$ \\
Female & $-2.37 \mathrm{-06}$ & $0.000415^{*}$ & 0.000191 & -0.000275 & $-0.000364^{* *}$ \\
& $(0.000195)$ & $(0.000229)$ & $(0.000210)$ & $(0.000182)$ & $(0.000172)$ \\
No. of ppl in hh & $0.0554^{* * *}$ & $0.0603^{* * *}$ & $0.0582^{* * *}$ & $0.0545^{* * *}$ & $0.0530^{* * *}$ \\
& $(0.00353)$ & $(0.00417)$ & $(0.00381)$ & $(0.00328)$ & $(0.00310)$ \\
Constant & $0.0250^{* * *}$ & $0.0236^{* * *}$ & $0.0243^{* * *}$ & $0.0241^{* * *}$ & $0.0239^{* * *}$ \\
& $(0.00113)$ & $(0.00134)$ & $(0.00122)$ & $(0.00106)$ & $(0.000997)$ \\
Observations & $0.288^{* * *}$ & $0.326^{* * *}$ & $0.305^{* * *}$ & $0.300^{* * *}$ & $0.289^{* * *}$ \\
R-squared & $(0.0300)$ & $(0.0340)$ & $(0.0319)$ & $(0.0290)$ & $(0.0276)$ \\
\hline
\end{tabular}

Notes: Robust standard errors are in parentheses

${ }^{* * *} p<0.01,{ }^{* *} p<0.05,{ }^{*} p<0.1$

1998-2008 results in statistically insignificant coefficients for the $L A * L E P$ interaction (see Table 4 for results). Since four states are considered treated starting in 1998 and two more in 1999, the introduction of SCHIP occurs at pretty much the same time as the passage of Medicaid access-improving language access laws for a third of the treated states. Thus, perhaps language access is being conflated with SCHIP. There is one piece of evidence that goes against this conjecture: the year dummies

Table 4 Language access and Medicaid take-up rates: 1998-2008 sample

\begin{tabular}{llllll}
\hline & $(1)$ & $(2)$ & $(3)$ & $(4)$ & $(5)$ \\
Income level cutoff & 20,000 & 22,500 & 25,000 & 27,500 & 30,000 \\
\hline LA & $-0.0296^{*}$ & -0.0209 & $-0.0357^{* *}$ & $-0.0340^{* * *}$ & $-0.0304^{* *}$ \\
LEP & $(0.0165)$ & $(0.0152)$ & $(0.0142)$ & $(0.0129)$ & $(0.0121)$ \\
& 0.00601 & 0.0158 & $0.0189^{* *}$ & $0.0163^{*}$ & $0.0193^{* *}$ \\
LA*LEP & $(0.0109)$ & $(0.0100)$ & $(0.00925)$ & $(0.00858)$ & $(0.00804)$ \\
& 0.0185 & 0.0131 & 0.00819 & 0.00181 & 0.00134 \\
Age & $(0.0120)$ & $(0.0111)$ & $(0.0103)$ & $(0.00955)$ & $(0.00896)$ \\
& $0.000724^{* *}$ & $0.000473^{*}$ & 0.000198 & -0.000129 & -0.000162 \\
Female & $(0.000307)$ & $(0.000284)$ & $(0.000262)$ & $(0.000242)$ & $(0.000228)$ \\
& $0.0556^{* * *}$ & $0.0543^{* * *}$ & $0.0517^{* * *}$ & $0.0490^{* * *}$ & $0.0467^{* * *}$ \\
No. of ppl in hh & $(0.00567)$ & $(0.00521)$ & $(0.00479)$ & $(0.00445)$ & $(0.00418)$ \\
& $0.0276^{* * *}$ & $0.0278^{* * *}$ & $0.0290^{* * *}$ & $0.0283^{* * *}$ & $0.0269^{* * *}$ \\
Constant & $(0.00187)$ & $(0.00175)$ & $(0.00160)$ & $(0.00150)$ & $(0.00141)$ \\
& $0.225^{* * *}$ & $0.207^{* * *}$ & $0.203^{* * *}$ & $0.203^{* * *}$ & $0.186^{* * *}$ \\
Observations & $(0.0448)$ & $(0.0423)$ & $(0.0398)$ & $(0.0377)$ & $(0.0346)$ \\
R-squared & 30,183 & 35,595 & 41,169 & 46,960 & 52,653 \\
\hline
\end{tabular}

Notes: Robust standard errors are in parentheses

${ }^{* * *} p<0.01,{ }^{* *} p<0.05,{ }^{*} p<0.1$ 
for 1997-2005 (and 1999-2002 in particular) in the results with 1994-2008 as the sample have rather negative coefficients, implying that Medicaid enrollment declined substantially. The coefficients on the 1999, 2000, 2001, and 2002 dummies are all larger than - 0.05-relative to 1994; Medicaid take-up in the entire sample declined by 5 percentage points or more almost immediately after SCHIP was introduced. What is more, there is nothing to suggest that SCHIP was more beneficial to LEP migrants than other low educational attainment, foreign-born households. This leads me to conclude that the non-results are due to minimizing variation for up to a third of the treated states. Because of this, the rest of the analysis will focus on 1994-2008 as the sample.

One source of the increase in Medicaid take-up rates could be from private insurance users switching to Medicaid. The language access laws are doing nothing to expand health insurance coverage if these laws result in the government crowding out private insurance, by encouraging private insurance users to use public insurance (Brown et al. 2007; Brown and Finkelstein 2008). Does increased access to government-funded insurance decrease the number of people covered by private health insurance? On the one hand, people might shift to government coverage because it is cheaper than buying private insurance. On the other hand, private insurance companies could use the translated Medicaid documents as a template for their own applications, lowering the costs of translating it themselves. To analyze this question, I run Eq. 1 with an indicator variable HCOVPRIV, which is 1 if the individual is covered by private health insurance and 0 otherwise, as the dependent variable. I run the regression with variety of income cut-offs, similar to the previous analysis on Medicaid take-up rates. Results are in Table 5. In all cases, the interaction coefficient is positive and statistically significant; language access laws lead to an increase in private health insurance coverage as well. The percentage point increase in coverage is actually higher for private insurance than Medicaid, implying that language

Table 5 Language access, insurance coverage, and crowd-out: private insurance

\begin{tabular}{llllll}
\hline & $(1)$ & $(2)$ & $(3)$ & $(4)$ & $(5)$ \\
Income level cutoff & 20,000 & 22,500 & 25,000 & 27,500 & 30,000 \\
\hline LA & $-0.0364^{* * *}$ & $-0.0427^{* * *}$ & $-0.0405^{* * *}$ & $-0.0347^{* * *}$ & $-0.0420^{* * *}$ \\
LEP & $(0.00919)$ & $(0.00864)$ & $(0.00829)$ & $(0.00796)$ & $(0.00772)$ \\
& $-0.0502^{* * *}$ & $-0.0569^{* * *}$ & $-0.0640^{* * *}$ & $-0.0648^{* * *}$ & $-0.0678^{* * *}$ \\
LA*LEP & $(0.00659)$ & $(0.00621)$ & $(0.00590)$ & $(0.00565)$ & $(0.00550)$ \\
& $0.0338^{* * *}$ & $0.0381^{* * *}$ & $0.0395^{* * *}$ & $0.0357^{* * *}$ & $0.0363^{* * *}$ \\
Age & $(0.00754)$ & $(0.00711)$ & $(0.00678)$ & $(0.00650)$ & $(0.00631)$ \\
& $0.000522^{* *}$ & $0.000612^{* * *}$ & $0.000798^{* * *}$ & $0.000972^{* * *}$ & $0.00115^{* * *}$ \\
Female & $(0.000210)$ & $(0.000199)$ & $(0.000190)$ & $(0.000182)$ & $(0.000176)$ \\
& -0.00492 & -0.00276 & -0.00295 & -0.00180 & -0.00316 \\
No. of ppl in hh & $(0.00360)$ & $(0.00340)$ & $(0.00325)$ & $(0.00311)$ & $(0.00301)$ \\
& $-0.0235^{* * *}$ & $-0.0259^{* * *}$ & $-0.0254^{* * *}$ & $-0.0263^{* * *}$ & $-0.0268^{* * *}$ \\
Constant & $(0.00104)$ & $(0.000972)$ & $(0.000943)$ & $(0.000905)$ & $(0.000871)$ \\
& $0.311^{* * *}$ & $0.329^{* * *}$ & $0.358^{* * *}$ & $0.364^{* * *}$ & $0.388^{* * *}$ \\
Observations & $(0.0325)$ & $(0.0309)$ & $(0.0305)$ & $(0.0293)$ & $(0.0283)$ \\
R-squared & 58,169 & 68,991 & 78,894 & 89,937 & 99,724 \\
\hline
\end{tabular}

Notes: Robust standard errors are in parentheses

${ }^{* * *} p<0.01,{ }^{* *} p<0.05,{ }^{*} p<0.1$ 
access laws improved private health insurance coverage more so than Medicaid coverage. With lower enrollment in private insurance compared to Medicaid in the sample, the almost 4 percentage point increase in private insurance is a $20 \%$ increase, substantially higher than the 5\% increase in Medicaid enrollment.

Unsurprisingly, running a similar regression with any health insurance coverage as the left-hand side variable shows that language access increased health insurance coverage by almost 6 percentage points for lower levels of household income. Results are in Table 6 . Thus, it does not appear that access to government coverage crowded out private insurance and might have in fact resulted in crowd in. One possible reason for this is that some of the laws actually required all health insurance providers, public and private, to provide language access. Furthermore, private insurers could have taken advantage of translated documents for Medicaid insurance applications and translated their own applications at much lower costs. This would improve insurance rates for LEP migrants who want private insurance. This is supported by the lower interaction coefficient for the lowest income cutoff-these individuals probably would not be able to afford private insurance, even if they preferred it to public insurance.

Sommers et al. (2012) point out that there is significant variation in Medicaid takeup rates across states. Differences in these language access laws, along with differences in the migrant populations in each state, could lead to heterogeneous effects from the language access laws across the different states. I am primarily concerned that one state might be driving the results. To check if this is the case, I run Eq. 1 as before, but I remove a state that has passed a language access law from the sample. I do this 22 times, omitting one state at a time. The results are similar for almost all the states. The problem arises when I remove California or New York from the sample. When either of these states are removed from the sample, the coefficient on the $L A * L E P$ interaction is still positive but no longer statistically significant. This suggests that language access laws tend to

Table 6 Language access, insurance coverage, and crowd-out: any insurance

\begin{tabular}{llllll}
\hline \multirow{2}{*}{ Income level cutoff } & $(1)$ & $(2)$ & $(3)$ & $(4)$ & $(5)$ \\
\hline LA & 20,000 & 22,500 & 25,000 & 27,500 & 30,000 \\
\hline \multirow{2}{*}{ LEP } & $-0.0530^{* * *}$ & $-0.0527^{* * *}$ & $-0.0527^{* * *}$ & $-0.0492^{* * *}$ & $-0.0530^{* * *}$ \\
& $(0.0112)$ & $(0.0103)$ & $(0.00965)$ & $(0.00904)$ & $(0.00861)$ \\
LA*LEP & $-0.0413^{* * *}$ & $-0.0424^{* * *}$ & $-0.0448^{* * *}$ & $-0.0433^{* * *}$ & $-0.0441^{* * *}$ \\
& $(0.00834)$ & $(0.00769)$ & $(0.00719)$ & $(0.00677)$ & $(0.00644)$ \\
Age & $0.0589^{* * *}$ & $0.0599^{* * *}$ & $0.0569^{* * *}$ & $0.0479^{* * *}$ & $0.0462^{* * *}$ \\
& $(0.00947)$ & $(0.00875)$ & $(0.00820)$ & $(0.00771)$ & $(0.00735)$ \\
Female & $0.00247^{* * *}$ & $0.00233^{* * *}$ & $0.00231^{* * *}$ & $0.00222^{* * *}$ & $0.00230^{* * *}$ \\
& $(0.000256)$ & $(0.000237)$ & $(0.000223)$ & $(0.000210)$ & $(0.000200)$ \\
No. of ppl in hh & $0.0492^{* * *}$ & $0.0504^{* * *}$ & $0.0474^{* * *}$ & $0.0475^{* * *}$ & $0.0453^{* * *}$ \\
& $(0.00452)$ & $(0.00416)$ & $(0.00389)$ & $(0.00364)$ & $(0.00345)$ \\
Constant & $-0.00291^{* *}$ & $-0.00384^{* * *}$ & $-0.00293^{* *}$ & $-0.00440^{* * *}$ & $-0.00487^{* * *}$ \\
& $(0.00142)$ & $(0.00130)$ & $(0.00122)$ & $(0.00115)$ & $(0.00109)$ \\
Observations & $0.570^{* * *}$ & $0.563^{* * *}$ & $0.577^{* * *}$ & $0.598^{* * *}$ & $0.615^{* * *}$ \\
R-squared & $(0.0400)$ & $(0.0380)$ & $(0.0362)$ & $(0.0352)$ & $(0.0336)$ \\
\hline
\end{tabular}

Notes: Robust standard errors are in parentheses

${ }^{* * *} p<0.01,{ }^{* *} p<0.05,{ }^{*} p<0.1$ 
increase the Medicaid take-up rates of LEP migrants, but the results vary across states, with California and New York being the primary source of increased take-up rates. Truncated results are in Table 7; the top row of results is from the regression on the full sample (Table 3, column 1).

Many of the language access laws target the Spanish-speaking population, either directly by requiring Spanish interpreters and translated documents or indirectly by requiring language access for significant LEP populations, of which Spanish speakers are included most of the time. Because of this attention to Spanish speakers in particular, one might expect to find that language access laws have a greater impact on Medicaid take-up rates for Hispanic populations. To examine if this is the case, I run the following difference-in-difference-in-difference regression:

$$
\begin{aligned}
M E D_{i, t}=\beta_{0} & +\beta_{1} L A_{i}+\beta_{2} L E P_{i, t}+\beta_{3} S P A N_{i}+\beta_{4}(L A * L E P) \\
& +\beta_{5}(L A * S P A N)+\beta_{6}(L E P * S P A N)+\delta(L A * L E P * S P A N) \\
& +\theta X_{i, t}+\gamma_{1} T_{t}+\gamma_{2} S_{i}+\varepsilon_{i}
\end{aligned}
$$

where all variables are similar to in Eq. 1 , and $S P A N_{i}$ is an indicator variable that is 1 if the individual is in a household with at least one adult who is defined as Spanish speaking and 0 otherwise. I run the regression with three different definitions for Spanish-speaking-the first has all Spanish-speaking countries as the Spanish-speaking definition; the second definition has only Puerto Rico and Mexico, since these two coun-

\begin{tabular}{|c|c|c|c|c|}
\hline Omitted state & Year LA enacted & $n$ omitted & $L A * L E P$ coefficient & Rob. std. errors \\
\hline full sample & - & - & $0.0182^{* *}$ & 0.00742 \\
\hline $\mathrm{AL}$ & 2004 & 237 & $0.0189^{* *}$ & 0.00743 \\
\hline$A R$ & 2005 & 241 & $0.0188^{* *}$ & 0.00743 \\
\hline CA & 1973 & 20434 & 0.00608 & 0.00829 \\
\hline $\mathrm{CO}$ & 1999 & 1400 & $0.0180^{* *}$ & 0.00747 \\
\hline DC & 2005 & 814 & $0.0179^{* *}$ & 0.00743 \\
\hline $\mathrm{HI}$ & 2007 & 851 & $0.0194^{* * *}$ & 0.00745 \\
\hline IL & 1993 & 2545 & $0.0211^{* * *}$ & 0.00750 \\
\hline IN & 1999 & 285 & $0.0176^{* *}$ & 0.00742 \\
\hline IA & 2000 & 576 & $0.0176^{* *}$ & 0.00744 \\
\hline KY & 1998 & 286 & $0.0185^{* *}$ & 0.00742 \\
\hline MD & 1998 & 684 & $0.0191^{* *}$ & 0.00744 \\
\hline MA & 1998 & 2119 & $0.0212^{* * *}$ & 0.00751 \\
\hline MN & 1985 & 714 & $0.0198^{* * *}$ & 0.00743 \\
\hline MT & 1998 & 125 & $0.0180^{* *}$ & 0.00742 \\
\hline NJ & 2002 & 2691 & $0.0200^{* * *}$ & 0.00759 \\
\hline NM & 1999 & 1383 & $0.0195^{* * *}$ & 0.00747 \\
\hline NY & 1989 & 9947 & 0.00597 & 0.00770 \\
\hline NC & 2007 & 1183 & $0.0176^{* *}$ & 0.00754 \\
\hline TN & 2005 & 305 & $0.0149^{* *}$ & 0.00743 \\
\hline TX & 2000 & 8678 & $0.0177^{* *}$ & 0.00800 \\
\hline WA & 2004 & 1013 & $0.0188^{* *}$ & 0.00747 \\
\hline WI & 1986 & 609 & $0.0172^{* *}$ & 0.00744 \\
\hline
\end{tabular}
tries are the primary source of Spanish-speaking migrants in the USA; in the third, only

Table 7 Coefficient on $L A * L E P$, removing "omitted state" from sample 
Mexican-borns are defined as Spanish speaking, as Mexico makes up most of the Hispanic migrant population. The coefficient on $L A * L E P, \beta_{4}$, will be positive and statistically significant if language access laws are beneficial to non-Spanish-speaking LEP migrants. If the hypothesis that Spanish-speaking LEP migrants benefit even more from language access due to the emphasis on providing Spanish translation services, then the coefficient $\delta$, on $L A * L E P * S P A N$, will be positive and statistically significant; $\beta_{5}$, the coefficient on $L A * S P A N$, will be positive and statistically significant if language access improves Medicaid take-up rates for Hispanic migrants that are in households not defined as LEP.

Results are in Table 8. There is no evidence that language access laws are particularly helpful to the Spanish-speaking population, with a negative, though statistically insignificant, coefficient on the triple interaction variable for the "all Spanish-speaking countries" definition of Spanish speakers. The negative coefficient on the Spanish-speaking variable for the "Mexico" definition of Spanish speakers suggests that my definition of Limited English Proficiency is limited. The positive coefficient on the $L E P$ variable and the very negative coefficient on the $L E P * S P A N$ interaction suggest that only Spanish-speaking LEP migrants are having difficulty obtaining Medicaid, while other LEP migrants are doing well with accessing Medicaid. A major concern is that even though non-Hispanic LEP migrants have little trouble with Medicaid take-up, language access is further improving their access to Medicaid, while Spanish speakers who are not defined as LEP do

Table 8 Language access and Medicaid take-up rates: Spanish speakers

\begin{tabular}{|c|c|c|c|}
\hline & (1) & (2) & (3) \\
\hline Spanish-speaking definition & All Spanish- speaking countries & Puerto Rico and Mexico & Mexico \\
\hline \multirow[t]{2}{*}{ LA } & -0.0128 & -0.0115 & $-0.0280^{* * *}$ \\
\hline & $(0.0108)$ & $(0.00992)$ & $(0.00975)$ \\
\hline \multirow[t]{2}{*}{ LEP } & $0.0755^{* * *}$ & $0.0530^{* * *}$ & $0.0585^{* * *}$ \\
\hline & $(0.0129)$ & $(0.00970)$ & $(0.00889)$ \\
\hline \multirow[t]{2}{*}{ SPAN } & $0.0386^{* * *}$ & $0.0584^{* * *}$ & $-0.0629^{* * *}$ \\
\hline & $(0.00833)$ & $(0.00839)$ & $(0.00932)$ \\
\hline \multirow[t]{2}{*}{ LA*LEP } & $0.0302^{*}$ & $0.0254^{* *}$ & 0.0148 \\
\hline & $(0.0169)$ & $(0.0118)$ & $(0.0109)$ \\
\hline \multirow[t]{2}{*}{ LA*SPAN } & $-0.0167^{*}$ & $-0.0265^{* * *}$ & 0.00170 \\
\hline & $(0.00972)$ & $(0.0100)$ & $(0.0108)$ \\
\hline \multirow[t]{2}{*}{ LEP*SPAN } & $-0.0876^{* * *}$ & $-0.0798^{* * *}$ & $-0.0806^{* * *}$ \\
\hline & $(0.0142)$ & $(0.0122)$ & $(0.0122)$ \\
\hline \multirow[t]{2}{*}{ LA*LEP*SPAN } & -0.00349 & 0.00757 & 0.0207 \\
\hline & $(0.0189)$ & $(0.0155)$ & $(0.0153)$ \\
\hline \multirow[t]{2}{*}{ Age } & $-1.20 e-05$ & $2.27 e-05$ & $-0.000369^{*}$ \\
\hline & $(0.000195)$ & $(0.000195)$ & $(0.000195)$ \\
\hline \multirow[t]{2}{*}{ Female } & $0.0553^{* * *}$ & $0.0555^{* * *}$ & $0.0535^{* * *}$ \\
\hline & $(0.00353)$ & $(0.00353)$ & $(0.00352)$ \\
\hline \multirow[t]{2}{*}{ No. of ppl in hh } & $0.0251^{* * *}$ & $0.0250^{* * *}$ & $0.0278^{* * *}$ \\
\hline & (0.00113) & $(0.00114)$ & $(0.00113)$ \\
\hline \multirow[t]{2}{*}{ Constant } & $0.259^{* * *}$ & $0.259^{* * *}$ & $0.316^{* * *}$ \\
\hline & $(0.0306)$ & $(0.0303)$ & $(0.0303)$ \\
\hline Observations & 78,894 & 78,894 & 78,894 \\
\hline R-squared & 0.191 & 0.191 & 0.194 \\
\hline
\end{tabular}

Notes: Robust standard errors are in parentheses ${ }^{* * *} p<0.01,{ }^{* *} p<0.05,{ }^{*} p<0.1$ 
worse after language access laws have been passed, according to the "all Spanish-speaking countries" and "Puerto Rico and Mexico" definition of Spanish speakers.

\section{Conclusions}

The benefits migrants gain from learning the destination language has been carefully studied by economists, but those who have difficulty acquiring the destination language do not have to suffer. Governments can help reduce inequalities from language barriers by promoting language access: providing translation services such as translated documents and interpreters at government organizations or requiring companies to do so. The USA has attempted to address this by requiring meaningful access to federally funded services even if an individual is a Limited English Proficient (LEP) migrant. Some states have enacted laws that cover even more institutions, to increase language access for LEP migrants. Many of these language access laws relate to increasing access to health care, by requiring translated documents or interpreters in hospitals or at insurance agencies.

In this paper, I make use of the heterogeneity in state language access laws to examine if Medicaid take-up rates among LEP migrants increased after the enactment of language access laws using a difference-in-difference model. I find that language access laws increase Medicaid take-up rates by 1.8 percentage points. This increase to governmentfunded health insurance has not come at the expense of private health insurance. In fact, quite the opposite has happened, with private health insurance coverage increasing after language access laws are enacted. The increase in Medicaid take-up rates varies by state, and California and New York appear to be major drivers of the increase in Medicaid takeup rates. Lastly, there is no evidence that Spanish speakers are benefiting from the laws more so than other LEP migrants, even though many of these laws are targeted at providing translation services to Spanish speakers; Spanish-speaking LEP migrants do not have higher take-up rates after the language access law was enacted compared to other LEP migrants.

Thus, it is not necessarily unreasonable for governments to promote translation services to address health issues of migrants. Migrants can benefit from language access, as evidenced by the increase in health insurance coverage after language access laws for Medicaid agencies have been enacted. Further, this government involvement does not necessarily result in crowd out. With that being said, there is still much research that needs to be done on language access and health care. There are three lines of research that need to be explored more carefully. First of all, what are the costs of providing translation services compared to the benefits individuals receive? Would it be cheaper and more efficient to help migrants learn English, instead? Second, are migrants benefiting from the increased access to Medicaid? Does the increase in Medicaid take-up rates result in healthier migrants? Are significant health events not having as much of an impact on finances? Lastly, are the positive outcomes from language access limited to Medicaid access? Do translated documents increase awareness of health issues? How much do interpreters help with communicating diagnoses for LEP migrants? Migrants will continue to arrive in large numbers, and not all these immigrants will be healthy and proficient in English; any concerns with public health will need to consider how to approach the language barriers that exist. 


\section{Endnotes}

${ }^{1}$ Like Medicaid, SCHIP is federally funded but state run and administered. SCHIP works as somewhat of a complement to Medicaid, though states use it differently-it can be used as a separate child health program, it can be used to expand Medicaid programs, or some combination of the two

${ }^{2}$ I get information about a country's languages spoken from the CIA Factbook.

${ }^{3}$ According to the "critical period hypothesis," individuals with exposure to a language during the critical period can acquire the language up to native ability. Exposure after the critical period, however, and an individual is less likely to be proficient. The authors consider ages 0-9 years as the critical period.

${ }^{4}$ I cannot easily identify whether states have passed language access laws after 2008 because the source I use to identify these laws was published in 2008.

${ }^{5}$ In most cases, this means Legal Permanent Resident.

\section{Appendix 1: Predicting the timing and number of health care access laws}

Two tests are used to provide evidence that the timing of the language access laws in health care are unpredictable. The first test looks at whether state characteristics can predict the number of health care language access laws in 2008 by regressing the number of health care language access laws on the 1970 state characteristics. The count is taken from the number of entries a state has in (Perkins and Youdelman 2008). The second follows (Hoynes and Schanzenbach 2009) and (Bailey 2012), using state characteristics to predict the timing of the Medicaid access-improving language access laws. The covariates used for both tests are the same state characteristics in Table 1.

Results for the first test are in Appendix 1: Table 9. For the first test, using the entire sample of states, only the percent of the population that is born in a non-English speaking country and the governor's party affect the number of health care language access laws (column 1). California is a major outlier in the number of health care laws, with

Table 9 Predicting the number of health care language access laws

\begin{tabular}{lllll}
\hline \multirow{2}{*}{ Sample } & $(1)$ & $(2)$ & $(3)$ & $(4)$ \\
& All states and D.C. & Less California & Treated states & $\begin{array}{l}\text { Treated states } \\
\text { less California }\end{array}$ \\
\hline Percent foreign-born & -11.22 & -26.76 & 159.5 & 183.0 \\
& $(196.1)$ & $(206.8)$ & $(177.9)$ & $(166.9)$ \\
Percent born in non-English & $583.9^{*}$ & 369.4 & 325.7 & 73.34 \\
speaking country & $(318.9)$ & $(249.8)$ & $(351.8)$ & $(222.3)$ \\
Percent with English as mother & 27.62 & -8.413 & 25.43 & -4.815 \\
tongue & $(84.50)$ & $(77.72)$ & $(82.41)$ & $(86.42)$ \\
Employed-to-unemployed ratio & -1.126 & -0.506 & $-2.005^{*}$ & $-1.053^{*}$ \\
& $(0.703)$ & $(0.399)$ & $(1.113)$ & $(0.505)$ \\
Total family income & -0.000728 & 0.000105 & 0.00209 & 0.00228 \\
& $(0.00245)$ & $(0.00168)$ & $(0.00334)$ & $(0.00217)$ \\
Governor's party & $10.57^{* *}$ & $9.192^{* * *}$ & $14.76^{*}$ & $14.19^{* *}$ \\
Constant & $(4.272)$ & $(3.366)$ & $(8.016)$ & $(5.630)$ \\
& -5.210 & 12.02 & -9.786 & -1.425 \\
Observations & $(78.86)$ & $(78.91)$ & $(75.96)$ & $(90.71)$ \\
R-squared & 51 & 50 & 28 & 27 \\
\hline
\end{tabular}

Notes: Robust standard errors in parentheses

${ }^{* * *} p<0.01,{ }^{* *} p<0.05,{ }^{*} p<0.1$. Democrat $=1$ and Republican $=2$ for "Governor's party" 


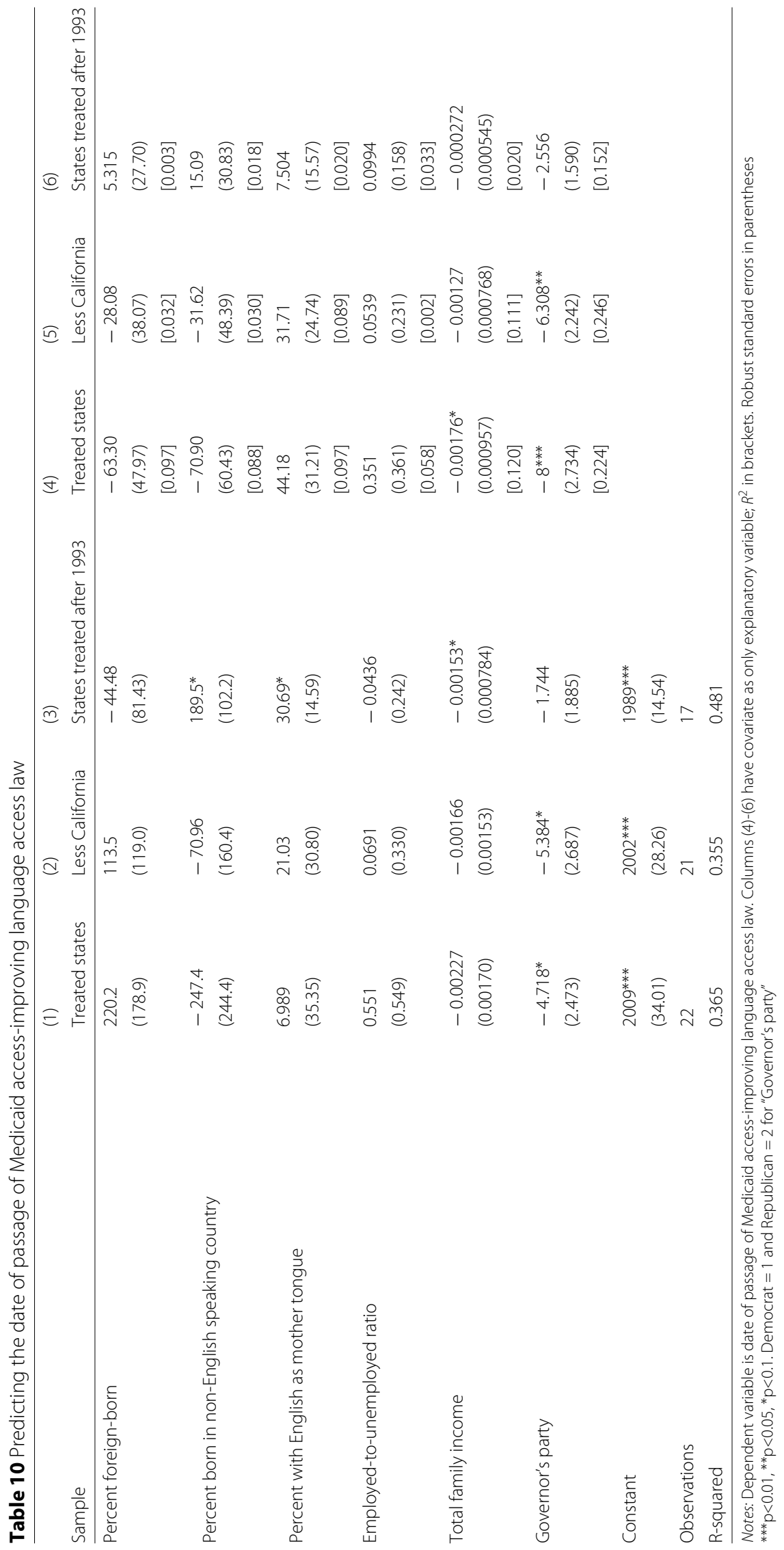


over 150, while no other states has more than 75; removing California from the sample, only the governor's party in 1970 predicts the number of health care language access laws in 2008 (column 2). Focusing in on states that have passed a Medicaid access-improving language access law, the employed-to-unemployed ratio is statistically significant at the $10 \%$ level (columns 3 and 4). The direction is negative, perhaps a little counterintuitive-the more people that are employed for each unemployed individual, the fewer health care language access laws there are. One might expect that a higher employed-to-unemployed ratio would encourage migrants to move to a state, thereby encouraging the passage of more laws. The governor's party stays positive and statistically significant; having a Republican governor in 1970 increases the number of health care language access laws in 2008. Aside from the governor's party, state characteristics seem to do little to predict migrant friendliness with respect to the number of health care language access laws.

The second test's results are in Appendix 1: Table 10. Results from regressing the date of passage on the covariates are in columns (1)-(3). Column (1) contains all states with known dates; column (2) takes out California, due to its early adoption of Medicaid access-improving language access laws; and column (3) contains only states that have passed Medicaid access-improving language access laws in the 1994-2008 sample. Governor's party is statistically significant again, but this time negative. Having a Democratic governor will lower the number of health care language access laws but result in earlier adoption of Medicaid access-improving language access laws. When limiting the sample to states that passed laws in the 1994-2008 sample, the percent of the population born in a non-English speaking birthplace, the percent of the population with English as a mother tongue, and total family income become statistically significant at the $10 \%$ level, while governor's party loses significance. The direction of some of these coefficients are again perhaps counterintuitive-having more a higher percent of the population with a non-English speaking birthplace is more likely to encourage migrants, thereby putting more pressure to pass a Medicaid access-improving language access law, but the coefficient indicates a later date of passage with a higher percent of the population born in a non-English speaking country.

Since there are only 22 states with known dates for the passage of Medicaid accessimproving language access laws, a regression with all the covariates might not be meaningful. To address this, separate regressions are run where only one covariate is used as the explanatory variable; results are in Table 10 columns (4)-(6). Total family income is barely statistically significant at the $10 \%$ level for all 22 states but loses significance as soon as California is dropped from the sample. $R^{2}$ values are reported to show the explanatory power of each covariate. Only governor's party can explain more than $20 \%$ of the variation. Since the governor's party is the most consistent explanatory variable for predicting the date of passage of Medicaid access-improving language access laws but predicts something almost opposite to the first test for the number of health care language access laws, I conclude that the passage of the Medicaid access-improving language access laws is unpredictable.

\section{Additional file}




\section{Acknowledgements}

I would like to thank Tim Halliday, Jeff Traczynski, Sumner La Croix, Andy Mason, and the participants of the 2016 APPAM Fall Research Conference and brownbag seminars at the University of Hawai'i, Mānoa Economics Department. I would like to thank the anonymous referee and the editor for the useful comments.

Responsible editor: Hartmut F. Lehmann

\section{Competing interests}

The IZA Journal of Development and Migration is committed to the IZA Guiding Principles of Research Integrity. The author declares that he has observed these principles.

\section{Publisher's Note}

Springer Nature remains neutral with regard to jurisdictional claims in published maps and institutional affiliations.

Received: 3 November 2017 Accepted: 25 April 2018

Published online: 27 November 2018

\section{References}

Altonji JG, Card D. The effects of immigration on the labor market: outcomes of less-skilled natives. In: Abowd JM, Freeman RB, editors. Immigration, trade, and the labor market. Chicago; 1991. p. 201-234.

Angrist JD, Lavy V. The effect of a change in language of instruction on the returns to schooling in Morocco. J Labor Econ. 1997;15:45-76.

Bailey MJ. Reexamining the impact of family planning programs on U.S. fertility: evidence from the war on poverty and the early years of Title X. Am Econ J Appl Econ. 2012;4(2):62-97.

Bleakley H, Chin A. Language skills and earnings: evidence from childhood immigrants. Rev Econ Stat. 2004;86:481-496.

Bleakley H, Chin A. Age at arrival, English proficiency, and social assimilation among U.S. immigrants. Am Econ J Appl Econ. 2010;2:165-192.

Brown J, Coe NB, Finkelstein A. Medicaid crowd-out and private long-term insurance demand: evidence from the Health and Retirement Survey. In: Poterba J, editor. Tax Policy and the Economy. vol. 21. Cambridge; 2007. p. 1-34.

Brown J, Finkelstein A. The interaction of public and private insurance: Medicaid and the long-term care insurance market. Am Econ Rev. 2008;98(3):1083-1102.

Chiswick BR. Speaking, reading, and earnings among low-skilled immigrants. J Labor Econ. 1991;9(2):149-70.

Chiswick BR, Miller PW. A model of destination language acquisition: application to male immigrants in Canada. Demography. 2001;38(3):391-409.

Chiswick BR, Miller P. Do enclaves matter in immigrant adjustments? City Community. 2005;4(1):5-35.

Feinberg E, Swartz K, Zaslavsky AM, Gardner J, Walker DK. Language proficiency and the enrollment of Medicaid-eligible children in publicly funded health insurance programs. Matern Child Health J. 2002;6(1):5-18

Hadler MW, Chen X, GonzaelzE, Roby DH. Limited English proficient hmo enrollees remain vulnerable to communication barriers despite language assistance regulations. Technical report, UCLA Center for Health Policy Research. 2013.

Hoynes HW, Schanzenbach DW. Consumption responses to in-kind transfers: evidence from the introduction of the food stamp program. Am Econ J Appl Econ. 2009;1 (4):109-139.

Khan AA, Sevilla C, Wieslander CK, Moran MB, Rashid R, Mittal B, Maliski SL, Rogers RG, Anger JT. Communication barriers among Spanish-speaking women with pelvic floor disorders: lost in translation. Female Pelvic Med Reconstr Surg. 2013;19(3):157-164.

Ku L, Jewers M. Health care for immigrant families: current policies and issues. Technical report, Migration Policy Institute. 2013.

Youdelman M. Federal laws and policies to ensure access to health care services for people with limited English proficiency. Technical report, National Health Law Program. 2009. Nathional Health Law Program \& The Access Project.

Perkins J, Youdelman M. Summary of state law requirements: addressing language needs in health care. Technical report, National Health Law Program. 2008.

Quan K, Lynch J. The high costs of language barriers in medical malpractice. Technical report, UC Berkeley School of Public Health and National Health Law Program. 2010.

Sommers B, Kronick R, Finegold K, Po R, Schwartz K, Glied S. Understanding participation rates in Medicaid: implications for the Affordable Care Act. Technical report, U.S. Department of Health \& Human Services. 2012.

Zong J, Batalova J. Limited English Proficient population of the United States. 2015. Migration Policy Institute. http:// www.migrationpolicy.org/article/limited-english-proficient-population-united-states/. Accessed 3 Nov 2017. 